\title{
Keeping advertisers honest - an overview of the regulation of the advertising of medicines and medical devices in Australia
}

\author{
Craig A. Davies, Head, Advertising and Export Section, Non-Prescription Medicines \\ Branch, Therapeutic Goods Administration, Canberra
}

\section{Summary \\ Australia has long-standing co-regulatory systems governing the advertising of therapeutic goods to consumers and healthcare professionals. These systems include representatives of all key stakeholder groups and are underpinned in law by the Commonwealth Therapeutic Goods Act 1989 and associated Regulations. The co-regulatory systems also include processes for handling complaints. These processes differ depending on the product involved and how it is advertised. Most complaints are made by rival companies rather than by consumers or health professionals. This lack of diversity in the source of complaints is seen by some as a weakness in the complaints system.}

Key words: drug industry, consumers, Therapeutic Goods Administration.

(Aust Prescr 2004;27:124-7)

\section{Introduction}

In Australia, the Therapeutic Goods Administration (TGA) is responsible for administering the Therapeutic Goods Act 1989 (the Act) and the accompanying Therapeutic Goods Regulations (the Regulations). The object of the legislation is to establish and maintain a national system of controls for the quality, safety, efficacy and timely availability of 'therapeutic goods' that are used in or exported from Australia.

Generally, therapeutic goods are required to be entered on the Australian Register of Therapeutic Goods (the Register) before they may be lawfully manufactured, supplied, imported or exported for use by humans. Additionally, the legislation prescribes requirements for 'advertisements' which, in relation to therapeutic goods, 'includes any statement, pictorial representation or design, however made, that is intended, whether directly or indirectly, to promote the use or supply of the goods'.

\section{Advertising controls - a co-regulatory approach}

Co-regulatory systems control the advertising of therapeutic goods to consumers and healthcare professionals. These systems include representatives of the regulated industry sectors, consumers, healthcare professionals, media, advertisers and government.

\section{Advertising to consumers}

The co-regulatory system governing advertising to consumers is legally underpinned by the Act and Regulations, which adopt the Therapeutic Goods Advertising Code (TGAC). This Code specifies detailed requirements for advertisements and aims to ensure that the marketing and advertising of therapeutic goods to consumers is conducted in a socially responsible manner that promotes the quality use of therapeutic goods and does not mislead or deceive the consumer. A copy of the TGAC may be downloaded from www.tgacc.com.au/codeList.cfm

The TGAC is administered by the Therapeutic Goods Advertising Code Council. This includes representatives from stakeholder groups and is established under the Therapeutic Goods Regulations. The role of the Council includes:

a considering the advertising requirements for therapeutic goods

- considering amendments to the TGAC

- making recommendations to the Commonwealth Minister for Health and Ageing.

\section{Mandatory pre-approval of consumer advertisements}

Advertisements to consumers which are broadcast, published or inserted in the mainstream media (such as television, radio, newspapers and magazines) are subject to mandatory pre-approval before publication or broadcast. This pre-approval is carried out, under delegated authority from the Commonwealth Department of Health and Ageing, by the Australian Self-Medication Industry (ASMI) and the Complementary Healthcare Council of Australia ( $\mathrm{CHC}$ ). These industry associations represent the sponsors and manufacturers of non-prescription (over-the-counter and complementary) medicines.

\section{Prescription medicines}

Prescription medicines are not subject to the provisions of the TGAC as it is unlawful to advertise these medicines to consumers. 


\section{Advertising prescription medicines to healthcare professionals}

Advertisements for prescription medicines are subject to the provisions of the Trade Practices Act 1974, section 22(5) of the Therapeutic Goods Act (which establishes an offence where therapeutic goods are advertised with indications other than those that have been accepted in the Register), and any other conditions which may be assigned to the marketing approval of the product.

Advertisements for prescription-only medicines (which may be published in professional journals) are not subject to mandatory pre-approval.

\section{Complaints resolution including industry self-regulation}

Included in the self-regulatory components of Australia's system for advertising controls are voluntary codes of practice with 'built-in' complaints handling mechanisms. These voluntary codes are administered by the industry associations - Medicines Australia (for prescription medicines) and ASMI and $\mathrm{CHC}$ (for non-prescription medicines).

The complaints committees of these industry associations consist of industry representatives and independent, external representatives (including healthcare professionals, consumer groups and theTGA). These self-regulatory complaints committees primarily consider complaints about 'nonmainstream' advertisements for therapeutic goods such as:

- leaflets, catalogues and brochures distributed via letterbox drop

- point-of-sale material, for example flyers and 'shelf-talkers'

- advertisements directed to healthcare professionals.

While requiring compliance with the legislative provisions, the industry codes of practice include additional, 'ethical/ industry' requirements which are not necessarily prescribed by law. The complaints committees can impose commercial sanctions and government agencies such as the TGA and the Australian Competition and Consumer Commission (ACCC) expect industry participants to comply with the findings of these committees, whether or not the company in question is a member of the particular industry association.

In the few cases where the complaints committees are unable to achieve a satisfactory outcome, the matter is then referred to the TGA and/or ACCC for consideration of appropriate action under the Therapeutic Goods Act or the Trade Practices Act 1974.

\section{Advertising to consumers}

The Complaints Resolution Panel is established under the Regulations to consider complaints relating to consumer advertisements for therapeutic goods appearing in the mainstream print media and broadcast media. The Panel is representative of the relevant stakeholder groups.
Complaints about these advertisements may be submitted to the Complaints Resolution Panel (see Box 1). A copy of the complaints form, procedure and related information may be obtained from theTherapeutic Goods Advertising Code Council web site.

\section{Over-the-counter and complementary medicines}

Generally, advertisements for non-prescription medicines may be directed at consumers or healthcare professionals. However, the Regulations prohibit the advertising to consumers of certain medicines included in Schedule 3 of the Standard for the Uniform Scheduling of Drugs and Poisons ('pharmacist-only' medicines).

Box 1

\section{Contact details for complaints}

Advertising to consumers (including advertisements for medical devices) in mainstream print and broadcast media

The Secretariat

Complaints Resolution Panel

PO Box 764

NORTH SYDNEY NSW 2059

Over-the-counter (pharmaceutical) medicines (advertising to consumers in other than mainstream media, and to health professionals)

The Executive Director

Australian Self-Medication Industry

PO Box 764

NORTH SYDNEY NSW 2059

Complementary medicines (advertising to consumers in other than mainstream media, and to health professionals)

The Executive Director

Complementary Healthcare Council of Australia

PO Box 104

DEAKIN WEST ACT 2600

Advertising of prescription-only medicines advertised to health professionals

Secretary, Code of Conduct Committee

Medicines Australia

Level 1

16 Napier Close

DEAKIN ACT 2600

Medical devices (advertising to consumers in other than mainstream media, and to health professionals)

Advertising and Export Section

Non-Prescription Medicines Branch

Therapeutic Goods Administration

PO Box 100

WODEN ACT 2606 
Advertisements for non-prescription medicines are subject to the Act, Regulations (including the provisions of theTGAC) and the industry codes of practice administered by the ASMI and $\mathrm{CHC}$. Complaints about advertisements in the mainstream media are considered by the Complaints Resolution Panel, while complaints about 'non-mainstream' advertisements are considered by the ASMI or CHC self-regulatory complaints committees.

Complaints about advertisements for over-the-counter (pharmaceutical) medicines may be submitted to the ASMI (see Box 1).

Complaints about advertisements for complementary (for example herbal, vitamin) medicines may be submitted to the $\mathrm{CHC}$ (see Box 1).

\section{Prescription-only medicines}

It is an offence under the Act to advertise prescription-only medicines to consumers. These medicines can only be advertised to healthcare professionals. The TGA's letter of marketing approval requires advertisements to comply with the requirements of the Medicines Australia Code of Conduct, irrespective of whether a company is an association member or not.

Complaints about advertisements for prescription medicines directed to healthcare professionals may be submitted to Medicines Australia (see Box 1). Copies of the Code of Conduct are available from the Medicines Australia web site.

\section{Medical devices}

Medical devices may be advertised directly to consumers. The regulatory requirements are similar to those which apply to the advertising of non-prescription medicines. However, there is currently no requirement for pre-approval of advertisements.

The Complaints Resolution Panel considers complaints about advertisements for medical devices appearing in the mainstream media. In the absence of a self-regulatory complaints committee, all other complaints about medical device advertisements may be submitted to the NonPrescription Medicines Branch of the TGA (see Box 1).

\section{Weakness in the co-regulatory system}

A continued weakness in the system is the lack of diversity in sources of complaint. The majority of complaints are generated from competitors within the regulated industry sectors. The active involvement of consumers and health professionals in particular should be encouraged.

The question about how to encourage such groups to lodge complaints continues to be asked. There have been, and continue to be, initiatives in this area. For example, during the mid-1990s the TGA, the ASMI and Medicines Australia published joint advertisements in medical and pharmacy journals advising health professionals of the mechanisms which exist to enable them to lodge complaints concerning the inappropriate promotion of therapeutic goods.

Education seminars for stakeholder groups are now held on a regular basis. For the past few years information about the various complaints handling processes has also been available on the internet.

\section{The role of the TGA}

The TGA is the primary government stakeholder and regulator within the co-regulatory system of advertising for therapeutic goods. It is one member of the Therapeutic Goods Advertising Code Council and regularly participates in the complaints committees of the industry associations.

In the majority of cases, the TGA will support the consideration of advertising complaints by these committees, as opposed to initiating its own independent action at the outset. However, when deemed necessary, the TGA will proceed with administrative and/or legal action in order to enforce the findings of complaints committees and, more broadly, to underpin the Australian system of advertising controls in the interests of public health and safety (see Box 2).

Approximately 5-10 times a year the TGA has to enforce the findings of the complaints system (see Box 2). This represents less than $3 \%$ of the complaints considered by the committees.

\section{Recent developments}

The Therapeutic Goods Amendment Act was passed in 2003. This transferred the offence provisions for advertising from the

\section{Box 2 \\ The TGA in action}

Last year, the Complaints Resolution Panel upheld a complaint against an advertisement published in a mainstream media magazine for a complementary medicine indicated for weight loss or weight management.

The breaches were considered to be serious enough to warrant the publication of a corrective advertisement and the Panel requested the sponsor to do this. The sponsor refused to comply with the request and the Panel subsequently made a recommendation to 'the Secretary' (TGA) to make an Order under the Regulations to enforce the earlier request.

The TGA agreed with the Panel's findings and recommendation, and proceeded to order the sponsor to publish the corrective advertisement. The sponsor ignored theTGA's Order and the TGA then proceeded to cancel the product from the Register on the grounds of nonconformity with the legislative advertising requirements. (Once cancelled from the Register, all further supply becomes unlawful.) 
Regulations to the Act, with a significant increase in penalties. The mandatory requirements for the pre-approval of broadcast advertisements have also been transferred to the Therapeutic Goods Act.

\section{Future directions}

The Australian and New Zealand Governments have agreed to harmonise the regulatory requirements for therapeutic goods. Throughout 2002 a review of the advertising of therapeutic goods in Australia and New Zealand was undertaken as part of the proposal to establish a trans-Tasman regulatory agency for therapeutic goods. The review aimed to develop an advertising scheme, including approval and complaints handling processes, that could be implemented as part of a joint agency.

A final report was issued in 2003 and is available from theTGA web site. The recommendations are now being considered and further developed in consultation with stakeholders. To facilitate this, the Interim Advertising Council has been established. Its recommendations for a trans-Tasman advertising model will be considered by the Australian and New Zealand Governments as part of the overall arrangements for establishing the new, joint regulatory agency.

A topic of interest to prescribers is whether direct-to-consumer advertising of prescription medicines will be permitted in Australia under the terms of the trans-Tasman agreement. Such advertising is currently legal in New Zealand, but it is unlikely that there will be a change to the current Australian policy.

\section{Further information}

Information about advertising therapeutic goods is available from several sources:

Therapeutic Goods Administration www.tga.gov.au

Therapeutic Goods Administration related legislation www.tga.gov.au/legis/index.htm

TGA Information Officer

1800020653 (telephone)

Therapeutic Goods Advertising Code Council www.tgacc.com.au

Industry associations

Medicines Australia

www.medicinesaustralia.com.au

Australian Self-Medication Industry

www.asmi.com.au

Complementary Healthcare Council of Australia www.chc.org.au

Medical Industry Association of Australia

www.miaa.org.au

Conflict of interest: none declared

\section{Self-test questions}

The following statements are either true or false (answers on page 133)

7. Medical devices cannot be advertised directly to the public.

8. Advertisements for prescription medicines directed to health professionals require pre-approval by the Therapeutic Goods Administration.

\section{The story of one complaint}

In November 2002 a member of the Editorial Executive Committee of Australian Prescriber noticed an advertisement from Sanofi-Synthelabo in the Qantas in-flight magazine. Although this advertisement could be read by members of the public, it contained the brand names of prescription-only drugs.

As this advertisement was a promotion directed at consumers a complaint was made to the Complaints Resolution Panel. However, the Complaints Resolution Panel did not deal with the complaint. It said that the advertisement was outside its jurisdiction, because direct-to-consumer advertisements for prescription medicines are illegal. The complaint was therefore redirected to the Therapeutic Goods Administration (TGA).

When nothing further was heard, the TGA was asked about the outcome of the complaint. The TGA advised that the matter had 'been addressed and the advertisement in question has been withdrawn'.

Although subsequent correspondence revealed why the TGA did not take any further action, a separate complaint about the same advertisement by another academic to Medicines Australia produced a different sanction. The Code of Conduct Committee of Medicines Australia ruled that the advertisement was 'a serious breach of the Code of Conduct as it promoted the use of a prescription-only product to members of the general public'. In contrast to theTGA, Medicines Australia published its assessment and imposed the maximum fine of $\$ 50000 .^{1}$

\section{Reference}

1. Medicines Australia. Code of Conduct Annual Report 2003. Canberra: Medicines Australia; 2003. 